\title{
Evaluation of tibial tray coronal plane alignment in total knee replacement using intramedullary JIG-a prospective study
}

\author{
Thokaloath R.S. ${ }^{1}$, Mohankumar E.G. ${ }^{2}$ \\ ${ }^{1}$ Dr. Rahul Sreenivasan Thokaloath, Lecturer, Orthopedics, Government Medical College Kottayam, Kerala, ${ }^{2}$ Dr. E.G. \\ Mohankumar, Head of the Department, Orthopedics, KIMS Al-Shifa Super Specialty Hospital, Perinthalmanna, \\ Malappuram, Kerala, India.
}

Corresponding Author: Dr. Rahul Sreenivasan Thokaloath, Lecturer, Orthopaedics, Government Medical College, Kottayam, Kerala, India. Email: rahul.thokaloath@gmail.com

\begin{abstract}
Introduction: Long term survivorship in total knee replacement [TKR] is significantly dependant on prosthesis alignment. In a standard total knee replacement, tibial component alignment is a key factor for the long-term success of the surgery. Materials and Methods: A prospective observational study on 176 subjects who underwent TKR with intramedullary jig for tibial alignment with a minimum follow up period of 6 months was conducted in the Department of orthopaedics, KIMS Al Shifasuper-specialty hospital, Kerala. The Tibial component alignmentwas measured by the Tibial Component Angle [TCA] and Error in Tibial trayalignment. The other outcome variables were knee score, functional score, and Tourniquet time. Results: The mean TCA in the study population was $90.56^{\circ} \pm 1.194^{\circ}$ ranging from $86.45^{\circ}$ to $94.05^{\circ}$. The mean error observed in tibial tray alignment was $-0.56 \pm 1.199$ degrees, ranging from -0.45 to +3.55 degrees. Accuracy of TCA within $90 \pm 2$ degrees was achieved in $91.48 \%$ of subjects. The mean knee score at $6 \mathrm{months}$ was $89.45 \pm 3.83$. The mean functional score at 6 months was $87.55 \pm 4.93$. The mean tourniquet time was $59.08 \pm 5.88$ minutes. Conclusions: Intramedullary tibial referencing guide can be used in TKR with great accuracy (91.48\%) to achieve desired coronal plane tibial component alignment $(90 \mathrm{o} \pm 2 \mathrm{o})$. When TCA was accurate, knee score and functional score were better than non-accurate TCA cases
\end{abstract}

Keywords: Tibial Component Angle [TCA], Total Knee Replacement [TKR], Total Knee Arthroplasty [TKA], intramedullary jig, Tibialtray alignment.

\section{Introduction}

Total knee replacement [TKR] surgery, or Total knee arthroplasty [TKA], is a highly effective procedure for end stage knee arthritis giving highly gratifying functional results. With increasing indications for TKR, younger patients are also undergoing TKR because of longer survival of the prosthesis [1,2]. Long term survivor ship in TKR is significantly dependant on prosthesis alignment and balancing. In a standard TKR, tibial component alignment [TCA] is a key factor for the long term success of the surgery [3-5].

This becomes more so important when we are using gap balancing technique. Out of the 6 bone cuts in TKA, probably the most important one is the tibial cut. The restoration of neutral mechanical alignment in femur and tibia, achieved in coronal and sagittal plane with the

Manuscript Received: $14^{\text {th }}$ November 2018

Reviewed: $24^{\text {th }}$ November 2018

Author Corrected: $30^{\text {th }}$ November 2018

Accepted for Publication: $5^{\text {th }}$ December 2018 transverse axis of knee made parallel to the ground results in best alignment of TKR [6,7]. Malposition of the components is the main cause of early failure [7]. Of the three planes, coronal plane mal-alignment is a major cause of wear, loosening, instability, failure and revision surgeries [8] and hence restoring it is one of the most important goals. Although the gold standard guide for achieving coronal plane alignment for the femoral cut is intramedullary jig $[9,10]$, a few popular choices exist for tibial cuts such as conventional intramedullary jig, conventional extra medullary jig or computer assisted navigation.

Conventional intramedullary and extra medullary techniques are used most commonly depending on the surgeon preferences and institutional protocols. It is less reliable to use an extra medullary guide in obese patients $[4,11]$ but on using intra medullary guide the positioning and orientation of the tibial cut is carried out 


\section{Original Research Article}

more accurately besides reduced surgical and tourniquet time $[3,9]$. The neutral mechanical alignment in tibia in the coronal plane means the tibial base plate of the tibial component of TKR should be perpendicular to the mechanical axis of tibia which is measured by the Tibial Component Angle [TCA] and error in tibial tray alignment [12]. In developing countries, the cheaper, easier, conven-tional alignment guides are used and studies on results of intramedullary guide regarding coronal plane alignment in Indian population is very limited.

Our hospital is using primarily intramedullary guide for tibial tray alignment. Hence, we carried out our study with the primary objective of measuring the TCA and the error in tibial tray alignment and our secondary objective was to compare the impact of accuracy in tibial tray alignment within $90^{\circ} \pm 2^{\circ}$ on knee score and functional score, and also measuretourniquet time, knee score and functional score in the study population.

\section{Materials and Methods}

Place of study: Department of orthopedics, Kims Al Shifa super-speciality hospital, Perinthalmanna Kerala, from October 2015 to July2016

Type of study: Prospective observational study

Sampling methods: Convenient sampling, Sample size was calculated as 108 by assuming the expected TCA angle to be 900 with a standard deviation of 3.2 as per study by Da Rocha Moreira Rezende B et al [13] and a null value of 89 degrees with $90 \%$ power and 5\% alpha error using the formula proposed by Kirkwood B et al[14]. Our primary outcome variables were TCA and error in tibial tray alignment. The Secondary outcome variables were Tourniquet time, knee score, functional score.

Sample size and collection: 176 subjects who underwent TKR with intramedullary jig for tibial alignment with a minimum follow up period of 6 months were the subjects. TCA, error in tibial tray alignment, Tourniquet time, knee score and functional score were obtained from all the samples (subjects). TCA is the medial angle formed between mechanical axis and the tibial base plate line [12,13]. It was measured using a previously published and validated method [14]. The error in tibial tray alignment was calculated by subtracting $90^{\circ}$ from TCA. If the TCA is less than $90^{\circ}$ then the tibial component is in varus and if it is more than $90^{\circ}$ then the tibial component is in valgus.
Inclusion criteria: We included subjects who had undergone primary TKR [cruciate retaining/Posterior stabilized].

Exclusion criteria: Subjects with extra articular deformities of tibia in sagittal or coronal plane or with implants that may impede the passage of intramedullary jig were excluded. We also excluded subjects who underwent revision TKR, and those who were lost to follow up and who developed periprosthetic fractures.

Statistical Methods: Data was entered in Microsoft excel. IBM SPSS version 22 was used for statistical analysis. Descriptive analysis was carried out by mean and standard deviation for quantitative variables, frequency and proportion for categorical variables.

Independent sample t-test/ ANOVA/Paired t- test was used to assess statistical significance for Quantitative outcome while Chi square test was used for Categorical outcome. $\mathrm{P}$ value $<0.05$ was considered statistically significant. IBM SPSS version 22 was used for statistical analysis.

Any specific score: Modified knee society score

Surgical process: Along with detailed history, Preoperative Clinical, Radiological assessment and basic laboratory investigations were done with measurement of knee society score.

All cases were operated with Smith and Nephew Genesis II total knee prosthesis under spinal or combined epidural and spinal anesthesia by the same surgeon. The tibial intramedullary jig entry point was marked at intersection of lines drawn from lateral tibial spine and medial $1 / 3 \mathrm{rd}$ of tuberosity and another line crossing the 1 st line at anterior $1 / 3 \mathrm{rd}$ and posterior $2 / 3 \mathrm{rd}$ junction using a marker pen.

Stem less tibial tray trial of appropriate size was used to further confirm the entry point. Total knee prosthesis cruciate retaining or posterior stabilized [depending on status of PCL and degree of deformity] was fixed.

TCA and error in tibial tray alignment were also measured. Post-operative radiological assessment and measure-ments were then done.

The subject was discharged from hospital to home on day 5 and was reviewed after 2 weeks for suture removal and was reviewed again at 6 weeks, 3 months and at 6 months. 


\section{Results}

A total of 176 subjects were included in the analysis.

Table-1: Summary of base line characteristics $(N=176)$

\begin{tabular}{|c|c|}
\hline Base line characteristics & Summary \\
\hline Age in years (Mean \pm S.D) & $64.42 \pm 7.182$ \\
\hline \multicolumn{2}{|c|}{ Gender } \\
\hline Male & $62(35.23 \%)$ \\
\hline Female & $114(64.77 \%)$ \\
\hline \multicolumn{2}{|l|}{ BMI category } \\
\hline Normal & $6(3.41 \%)$ \\
\hline Over weight & $136(77.27 \%)$ \\
\hline Obese & $34(19.32 \%)$ \\
\hline \multicolumn{2}{|c|}{ Side } \\
\hline Right & $91(51.70 \%)$ \\
\hline Left & $85(48.30 \%)$ \\
\hline \multicolumn{2}{|l|}{ Pre-op coronal plane deformity } \\
\hline Genu varum & $158(89.77 \%)$ \\
\hline Genu valgum & $18(10.23 \%)$ \\
\hline \multicolumn{2}{|c|}{ Diagnosis } \\
\hline Osteoarthritis (OA) & $166(94.3 \%)$ \\
\hline Rheumatoid arthritis (RA) & $7(4.0 \%)$ \\
\hline Post traumatic arthritis (PA) & $2(1.1 \%)$ \\
\hline Osteonecrosis $(\mathrm{ON})$ & $1(0.6 \%)$ \\
\hline $\begin{array}{l}\text { Tibial component angle }[\mathrm{TCA}] \text { in degrees } \\
(\text { Mean } \pm \mathrm{SD})\end{array}$ & $90.56 \pm 1.194$ \\
\hline Error in tibial tray alignment in degrees (Mean $\pm \mathrm{SD})$ & $-0.56 \pm 1.199$ \\
\hline \multicolumn{2}{|c|}{ Accuracy } \\
\hline Yes & $161(91.48 \%)$ \\
\hline No & $15(8.52 \%)$ \\
\hline
\end{tabular}

Among the study population, the mean age was $64.42 \pm 7.182$ years. Among the study population male participants were $62(35.23 \%)$ reaming $114(64.77 \%)$ were female participants. Among the study population, $6(3.41 \%)$ were normal, 136 (77.27\%) were overweight and 34 (19.32\%) were obese.

Among the study population, side was right in 91 (51.70\%) subjects and the remaining 85(48.30\%) had left. Among the study population, pre-op coronal plane deformity was genu varum in $158(89.77 \%)$ subjects and the remaining 18 $(10.23 \%)$ had genu valgum.

Among the study population, diagnosis was Osteoarthritis (OA) in 166 (94.3\%), Rheumatoid arthritis (RA) in 7(4.0\%), Post traumatic arthritis (PA) in 2(1.1), and Osteonecrosis $(\mathrm{ON})$ in $1(0.6 \%)$ respectively.

Among the study population, the mean tibial component angle (TCA) was $90.56^{\circ} \pm 1.194^{\circ}$ in degrees. Among the study population, the mean error observed was $-0.56 \pm 1.199$ in degrees. Among the study population accuracy was achieved in $161(91.48 \%)$ and accuracy was not achieved in 15 (8.52\%) of subjects (Table 1). 
Table-2: Descriptive analysis of post-operative deformity and complications in the study population $(\mathrm{N}=176)$

\begin{tabular}{|c|c|}
\hline \multicolumn{1}{|c|}{ Post-operative deformity and complications } & Summary \\
\hline \multicolumn{2}{|c|}{ Post-op coronal plane deformity } \\
\hline Valgus & $6(3.41 \%)$ \\
\hline Varus & $9(5.11 \%)$ \\
\hline No deformity & $161(91.48 \%)$ \\
\hline \multicolumn{2}{|c|}{ Complications detected if became symptomatic } \\
\hline Yes & $2(1.14 \%)$ \\
\hline No & $174(98.86 \%)$ \\
\hline
\end{tabular}

Among the study population, post-op coronal plane deformity was valgus in $6(3.41 \%)$ subjects and the remaining $9(5.11 \%)$ had varus deformity. Among the study population, post-operative complications were detected in $2(1.14 \%)$ of study population (Table 2 ).

Table-3: Descriptive analysis for other post-operative parameters in study population $(\mathrm{N}=176)$

\begin{tabular}{|c|c|}
\hline Parameter & Mean \pm SD \\
\hline Tourniquet time in minutes & $59.08 \pm 5.879$ \\
\hline Knee score at 6 months & $89.45 \pm 3.831$ \\
\hline Functional score at 6 months & $87.55 \pm 4.927$ \\
\hline
\end{tabular}

Among the study population, the mean tourniquet time was $59.08 \pm 5.879$ minutes. Among the study population, the mean knee score at $6^{\text {th }}$ month was $89.45 \pm 3.831$. Among the study population, the mean functional score at $6^{\text {th }}$ month was $87.55 \pm 4.927$.

Table-4: Comparison of mean tibial component angle in degrees across study groups $(\mathrm{N}=176)$

\begin{tabular}{|c|c|c|c|c|c|}
\hline \multirow{2}{*}{ BMI category } & Mean \pm SD & \multirow{2}{*}{$\begin{array}{c}\text { Mean } \\
\text { difference }\end{array}$} & \multicolumn{2}{|c|}{$\mathbf{9 5 \%}$ confidence intervalfor mean } & \multirow{2}{*}{ P value } \\
\cline { 4 - 5 } & & & lower bound & upper bound & \\
\hline Normal & $90.33 \pm 0.554$ & & & & \\
\hline Over weight & $90.61 \pm 0.846$ & 0.278 & -0.708 & 1.265 & 0.578 \\
\hline Obese & $90.43 \pm 2.132$ & 0.10 & -0.943 & 1.152 & 0.844 \\
\hline
\end{tabular}

The mean tibial component angle in degrees among normal group was $90.33 \pm 0.554,90.61 \pm 0.846$ among over weight group and $90.43 \pm 2.132$ among obese group. Considering normal group as base line, the mean difference of tibial component angle in degrees (0.278) in over weight group was statistically not significant ( $\mathrm{P}$ value 0.578$)$ and obese group (0.10) was also statistically not significant (P value 0.844$)$. (Table 4 )

Table-5: Comparison of mean knee score at 6 months across study groups $(n=176)$

\begin{tabular}{|c|c|c|c|c|c|}
\hline \multirow[t]{2}{*}{ Accuracy } & \multirow{2}{*}{ 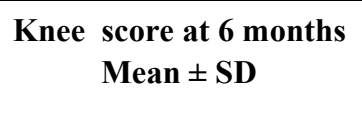 } & \multirow[t]{2}{*}{ Meandifference } & \multicolumn{2}{|c|}{$95 \% \mathrm{CI}$} & \multirow[t]{2}{*}{ p value } \\
\hline & & & lower & upper & \\
\hline Yes & $90 \pm 3.372$ & \multirow[t]{2}{*}{6.40} & \multirow[t]{2}{*}{4.59016} & \multirow[t]{2}{*}{8.20984} & \multirow[t]{2}{*}{$<0.001$} \\
\hline No & $83.6 \pm 3.660$ & & & & \\
\hline
\end{tabular}

The mean of knee score at 6 months was $90 \pm .3 .372$ in subjects with accuracy and without accuracy 83.6 \pm 3.660 . The mean difference $(6.40)$ between two group was statistically significant (P value $<0.001)$. 
Original Research Article

Table-6: Comparison of mean functional score at 6months across study groups $(\mathrm{N}=176)$

\begin{tabular}{|c|c|c|c|c|c|}
\hline \multirow{2}{*}{ Accuracy } & \multirow{2}{*}{$\begin{array}{c}\text { Functional score at6months } \\
\text { Mean } \pm \text { SD }\end{array}$} & \multirow{2}{*}{$\begin{array}{c}\text { Mean } \\
\text { difference }\end{array}$} & \multicolumn{2}{|c|}{$\mathbf{9 5 \%}$ CI } & \multirow{2}{*}{ P value } \\
& & & lower & upper & \\
\hline Yes & $88.32 \pm 3.910$ & 8.99 & 6.72602 & 11.25327 & $<0.001$ \\
\hline No & $79.33 \pm 7.037$ & & & & \\
\hline
\end{tabular}

The mean of functional score at 6 months was $88.32 \pm 3.910$ in subjects with accuracy and without accuracy $79.33 \pm$ 7.037. The mean difference $(8.99)$ between two group was statistically significant $(P$ value $<0.001)$ difference across the group is (8.99). It is statistically significant ( $\mathrm{p}$ value $<0.001$ ).

\section{Discussion}

One of the most common major surgeries performed to alleviate pain caused by moderate to severe knee arthritis is TKR. In our study, from October 2015 to July 2016, 176 patients underwent TKR using intra medullary jig at Kims Al Shifasuper-specialty hospital, Perinthalmanna, Kerala. If a patient had undergone bilateral TKR both knees were considered separately. About 8 patients had simultaneous bilateral TKR in a single sitting. The idealtibial component angle should be $90^{\circ} \pm 2^{\circ}[13]$. If the Error intibial tray alignment was more than $+2^{\circ}$, it was considered as varus deformity [tibial component angle $<88^{\circ}$ ] less than $-2^{\circ}$ was considered as valgus deformity [tibial component angle $\left.>92^{\circ}\right]$.

The mean age group of the subjects in our study was $64.42 \pm 7.182$ years almost similar to that observed by Reed MR et al [4] with 69 years and, Cashman JP et al [15] with 68.9 years. In our study group, majority were females constituting to about $64.74 \%$ of the study group higher than that reported by Reed MR et al[4] with $48.15 \%$ but lower than reported by Cashman JP et al[15] (79\%). In our study, $51.7 \%$ of surgeries were done on right knee higher than that reported by karade $\mathrm{V}$ et al [13] with $44.44 \%$. In our study, $89.77 \%$ of them had genu varum as pre-op coronal plane deformity as reported by other authors $[4,13]$ while $94.3 \%$ of subjects had osteoarthritis as pre-op diagnosis in our study similar to that reported by Reed MR et al[4] with $94.44 \%$.

In our study, the mean TCA was $90.56^{\circ} \pm 1.94^{\circ}$ which was similar to that reported by Reed MR et al [4] with a Mean TCA of 90.8 degrees. da Rocha Moreira Rezende $\mathrm{B}$ et $\mathrm{al}[16]$ in their study reported a mean of 90.3 degrees. In our study, the mean error observed in TCA was $-0.56^{\circ} \pm 1.99^{\circ}$ and similarly Karade V et al [13] also observed a mean error in TCA of $-0.34^{\circ}+/-2.3^{\circ}$. In our study, the Mean error was less compared to the Studies by Blakeney WG et al [17] and Chin PL et al [18].
Proper alignment of TKA prosthesis requires that the tibial component stem be parallel to mechanical axis of tibia[19]. As the tibial component base plate aligns itself along the cut plane, an accurate alignment of the cut plane with respect to the anatomical axis of the bone becomes very important. The cut should be perpendicular to the anatomical axis of the tibia. In our study, the accuracy within $90^{\circ} \pm 2^{\circ}$ was achieved in $91.48 \%$ of cases, which was higher than that observed by Reed MR et al [4] with $85 \%$ of the cases while Karade V et al [13] observed a very lower percentage with only $67 \%$ in the optimal range.

The accuracy obtained by intramedullary jig in our study was higher than the accuracy of most of the studies published in the literature using either intramedullary or extra medullary jig. But in the study by Cashman JP et al [15] all subjects were within two standard deviations of the mean alignment. In our study, the most severe post-op varus angle was $86.45^{\circ}$ while valgus angle was $94.05^{\circ}$.

In our study, when TCA was accurate, then knee score and functional score was better on comparison with non-accurate TCA. In our study, the difference in TCA between various categories of BMI didn't have any influence on TCA while using intramedullary jig. It establishes that intramedullary jig can be used in obese persons to get good accuracy in situation where extramedullary jig produces difficulty to find anatomical landmarks to align.

However, Lozano et al [11] examined obese patients and found no difference in the alignment of the tibial component between intra and extramedullary guides but he observed a reduced tourniquet time associated with the intramedullary guide. This is justified by the fact that the positioning and orientation of the tibial cut with intramedullary referencing is carried out more rapidly as anatomical references are not needed and the correct orientation is guided by the anatomical axis of the tibia. 


\section{Original Research Article}

One of the limitations of our study was that only coronal plane alignment was considered as it is known to be associated with a poor outcome. Our study had only short follow up of 6 months duration. Patients were not evaluated with devices to know the effect of opening the tibial marrow canal.

\section{Conclusion}

We conclude that intramedullary tibial referencing guide can be used in TKR with great accuracy $(91.48 \%)$ to achieve desired coronal plane tibial component alignment $\left(90^{\circ} \pm 2^{\circ}\right)$. When TCA was accurate, knee score and functional score were better than non-accurate TCA cases emphasizing the results from various studies that accurate placement of the implant may have a role in long term survival of the implant. High BMI did not affect the accuracy of tibial component angle in our cases using intramedullary jig. The accuracy of TCA using intramedullary jig in our study was better compared to accuracy using extramedullary jig in most of the published studies.

The First author of this article conducted the study after getting ethical clearance under the guidance of second author. Discussion was written by the second author. Sample selection, recruitment, Data collectionand analysis were done by the first author. This study was done entirely by using instruments and implants of a particular manufacturer and hence the results may not be generalized, which emphasizes the need for large studies involving commonly used implants across India.

In developing countries like India, the cheaper and conventional alignment guides are still used but data regarding accuracy of intramedullary tibial referencing guide in TKR was very limited. Our study adds further knowledge that intramedullary tibial referencing guide can be used in TKR with great accuracy to achieve desired coronal plane tibial component alignment.

Conflict of interest: None declared.

Funding: Nil, Permission from IRB: Yes

\section{References}

1. Mason JB, Fehring TK, Estok R, et al. Meta-analysis of alignment outcomes in computer-assisted total knee arthroplasty surgery. J Arthroplasty. 2007 Dec;22(8): 1097-106.

2. Ethgen $\mathrm{O}$, Bruyère $\mathrm{O}$, Richy $\mathrm{F}$, et al. Health-related quality of life in total hip and total knee arthroplasty. A qualitative and systematic review of the literature. J Bone Joint Surg Am. 2004 May;86-A(5):963-74. / s 0883-5403(98)90055-9
3. Maestro A, Harwin SF, Sandoval MG, Vaquero DH, Murcia A. Influence of intramedullary versus extramedullary alignment guides on final total knee arthroplasty component position: a radiographic analysis. J Arthroplasty. 1998;13(5):552-8. doi: 10.1016

4. Reed MR, Bliss W, Sher JL, et al. Extramedullary or intramedullary tibial alignment guides: a randomised, prospective trial of radiological alignment. J Bone Joint Surg Br. 2002 Aug;84(6):858-60.

5. Abdel MP, Oussedik S, Parratte S, et al. Coronal alignment in total knee replacement: historical review, contemporary analysis, and future direction. Bone Joint J. 2014 Jul;96-B(7):857-62. doi: 10.1302/0301-620X.96 B7. 33946 .

6. Windsor RE, Scuderi GR, Moran MC, et al. Mechanisms of failure of the femoral and tibial components in total knee arthroplasty. Clin OrthopRelat Res. 1989 Nov;(248):15-9; discussion 19-20.

7. Fehring TK, Odum S, Griffin WL, et al. Early failures in total knee arthroplasty. Clin OrthopRelat Res. 2001 Nov;(392):315-8.

8. Berend ME, Ritter MA, Meding JB, et al. Tibial component failure mechanisms in total knee arthroplasty. Clin OrthopRelat Res. 2004 Nov; (428): 26-34.

9. Zeng HB, Ying XZ, Chen GJ, Yang XQ, Lin DD, Li $\mathrm{ZJ}$, et al. Extramedullary versus intramedullary tibial alignment technique in total knee arthroplasty:A metaanalysis of randomized controlled trials.Clinics(Sao Paulo). 2015; 70 (10):714-9. doi:10.6061/ clinics/ 2015(10)10

10. Ritter MA, Faris PM, Keating EM, et al. Postoperative alignment of total knee replacement. Its effect on survival. Clin OrthopRelat Res. 1994 Feb; (299): 153-6.

11. Lozano LM, Segur JM, Maculé F, et al. Intramedullary versus extramedullary tibial cutting guide in severely obese patients undergoing total knee replacement: a randomized study of 70 patients with body mass index $>35 \mathrm{~kg} / \mathrm{m} 2$. Obes Surg. 2008 Dec;18 (12): 1599-604. doi: 10.1007/s11695-008-9564-1. Epub 2008 May 31.

12. Patil S, D'Lima DD, Fait JM, et al. Improving tibial component coronal alignment during total knee 